www.jmscr.igmpublication.org

Index Copernicus Value: 79.54

ISSN (e)-2347-176x ISSN (p) 2455-0450

crossref DOI: https://dx.doi.org/10.18535/jmscr/v7i5.52

\title{
Assessment of Awareness of Caregivers on Childhood Immunization and Reasons for Incomplete Immunization in Damoh District Madhya Pradesh
}

\author{
Authors \\ Dr Ram Kumar Panika, Sunil K Guleri* \\ Department of Community Medicine, Bundelkhand Medical College Sagar, Madhya Pradesh, India \\ *Corresponding Author \\ Dr Sunil Kant Guleri \\ Department of Community Medicine, Bundelkhand Medical College Sagar, Madhya Pradesh, India \\ Email:drsunilmdpsm@gmail.com, Contact No.: 9752701650
}

\begin{abstract}
India has one of the largest universal immunization programs in the world with large involvement of money and manpower, and multiple agencies working together still thousands of children still die from VaccinePreventable diseases each year. Lack of awareness among caregivers is one of great barrier for nonimmunization or partial immunization of children. This study has been conducted to assess the knowledge, and practice of caregivers about their understanding of childhood immunization in Damoh district of Bundelkhand region of Madhya Pradesh. 360 houses were with child below 3 years age were surveyed and caregivers were interviewed using predesigned and pretested questionnaire regarding to assess the knowledge, attitude and practice of parents about child immunization. Multistage random sampling was used to select 10 houses each from 02 wards/ mohallas of each 03 subcentres of each 06 PHC (primary health centre) in Damoh. Only 192(53.33\%) of the caregivers knew when vaccination was to be initiated and $50 \%$ were aware when the vaccination get completed. Among 360 children of selected houses 107 (29.72\%) children were partially immunized. Lack of awareness of next/further dose of vaccine was found to be the major reason (25.23\%) for incomplete immunization. So there is a need to increase awareness and knowledge about the benefits of vaccination, as well as the potential disadvantage of partial immunization. IEC (information, education and communication) activities must be increased in immunization clinics, session sites and in mass media to improve its the awareness of community.

Keywords: immunization, knowledge, attitude.
\end{abstract}

\section{Introduction}

Immunization is one of the most effective methods of preventing childhood diseases. ${ }^{[1]}$ It is a key strategy to child survival which significantly lowers morbidity and mortality rates in children. ${ }^{[2]}$ The Government of India launched EPI in 1978 with objective of reducing mortality and morbidity from vaccine preventable diseases of childhood. ${ }^{[3]}$ The program was revised and renamed as Universal Immunization Program (UIP) in 1985 focusing more on infants and pregnant mothers. ${ }^{[4]}$ India has one of the largest universal immunization programs in the world in terms of quantities of vaccines used, number of beneficiaries covered, geographical spread and manpower involved. India spends approximately 
20,000 million INR every year in immunization program to immunize children against vaccine preventable diseases. ${ }^{[1]}$ While the impact of Immunization on childhood morbidity \& mortality has been great, its full potential has yet to be reached. Thousands of children still die from Vaccine- Preventable diseases each year. ${ }^{[5]}$ despite the concerted efforts of the government and other health agencies, a large proportion of vulnerable infants and children in India remain unimmunized. India has the highest number (approximately 10 million) of such children in the world. In India only $43.5 \%$ of children in India received all of their primary vaccines by 12 months of age. ${ }^{[6]}$ In the past few decades immunization coverage rates have improved sufficiently in developed countries whereas most of the developing countries are still struggling with low rates. ${ }^{[7]}$ One of the major barriers for less immunization coverage in India are huge population with relatively high growth rate. Lack of awareness is another great barrier for non-immunization or partial immunization. Cultural diversity is in India making the complete vaccination coverage task more complex. Negative news in Media administration also has contributed for the decreased coverage of vaccines among certain communities. To overcome all these barriers, it is very important to increase the awareness about the vaccination among the public. ${ }^{[8]}$ Vaccine hesitancy of the parents has been increased due to their own concerns about vaccine and AEFIs and anti vaccine movement is encouraging them to refuse vaccination for their children. Unfortunately the refusal of parents may have been shown to increase the risk of vaccine preventable diseases. ${ }^{[9]}$ The knowledge of parents is an important factor for better immunization coverage. Mother's educational status and knowledge is clearly associated with coverage of immunization. Less knowledge among mothers bring negative attitude and fear which leads to effect immunization status of their children. ${ }^{[10]}$ Worldwide many studies have reported on mother's knowledge, attitudes and practice regarding children immunization and showed that successful immunization depends on parent's positive attitude and knowledge. ${ }^{[11]}$ Mother's knowledge and practices play a major role in achieving complete immunization before first birthday of the child. This study has been conducted to assess the knowledge, and practice of caregivers about their understanding of childhood immunization in Damoh district of Bundelkhand region of Madhya Pradesh

\section{Material and Methods}

It is a cross-sectional study carried out in district Damoh during July 2018- November 2018. Damoh is a district in Bundelkhand region in Sagar division of Madhya Pradesh with an area of 7306 square kilometers and population of 1264219 (2011 census). The district is served by a district hospital, seven community health centers and fifteen primary health centers. for the selection of study sample multistage random sampling was used. Among 15 PHCs, 6 PHCs were randomly selected. From each $\mathrm{PHC}$ area 3 subcentres (SCs), from each subcentres 02 wards/mohalla were selected randomly. In each ward /mohalla 10 consecutive houses with child below 03 years were surveyed. The houses where child ages below 03 years were not present were excluded from the study. Thus a total of 360 (6PHCx3SCx 2 mohalla $\mathrm{x} 10$ houses $=360$ ) caregivers were interviewed using predesigned and pretested questionnaire regarding to assess the knowledge, attitude and practice of parents about child immunization. The immunization status of youngest child of the house surveyed was also assessed. The data were collected and analyzed in excel using percentage and proportions.

\section{Results}

As for as Demographic Profile of Caregivers is concerned out of 360 caregivers interviewed $157(43.61 \%)$ belonged to $21-30$ yrs age group this was followed by 139(38.61\%) who were from 31$40 \mathrm{yrs}$ of age group. $06.94 \%$ caregivers were more than $40 \mathrm{yrs}$ and $10.83 \%$ were less than 20 years. With regard to education status, $90(25.00 \%)$ were 
illiterate, $72(20.00 \%)$ completed primary schooling, $82(22.77 \%)$ received educations up to middle, $18.05 \%$ completed secondary schooling and remaining $11.38 \%$ caregivers were graduate and above.

By employment 115(31.94\%) caregivers were employed and remaining $68.05 \%$ were either unemployed or housewife. Religion wise majority of caregivers 261(72.50\%) belonged to Hindu religion, $11.94 \%$ were Muslims and rest of $15.55 \%$ were from other religions (Table 01). With regard to Knowledge regarding childhood immunization around 192(53.33\%) of the caregivers knew when vaccination was to be initiated and $50 \%$ were aware when vaccination get completed, a majority of the mothers $56.94 \%$ believed that vaccines are safe and $48.05 \%$ caregiver consider vaccine are beneficial, $31.38 \%$ mothers were aware of age related vaccination, only $0.55 \%$ caregivers knew vaccine preventable disease (Table 02). The main source of information regarding vaccination was health workers 205 mainly through the Asha worker, other source of information were Aaganwadi worker, Neighbours/ Relatives, hospital and TV/ Radio (Figure 01). Age specific Immunization Status revealed that $107(29.72 \%)$ children partially immunized, remaining 253(70.27\%) children were completely immunized (Table 04). Among 360 children Around 107 (29.72\%) children were partially immunized. Lack of awareness of next/further dose $(25.23 \%)$ was found to be the major reason for incomplete immunization. Other reasons for incomplete immunization were lack of time $(14.95 \%)$, certain family problems (12.14\%), child illness (11.21\%), inconvenient time of session for working women $(8.41 \%)$, mothers were unaware of age related vaccination (04.67\%), Deficient information of place and time for session (10.28\%), Fear of side effect $(07.47 \%)$, Unavailability of vaccines $(05.60 \%)$ (Table 05).
Table 1: Demographic Profile of Caregivers

\begin{tabular}{|c|c|c|}
\hline $\begin{array}{l}\text { Demographic Profile of } \\
\text { Caregivers }\end{array}$ & No. & $\%$ \\
\hline \multicolumn{3}{|l|}{ Age Group } \\
\hline$<20$ years & 39 & 10.83 \\
\hline $21-30$ years & 157 & 43.61 \\
\hline $31-40$ years & 139 & 38.61 \\
\hline$>40$ years & 25 & 06.94 \\
\hline \multicolumn{3}{|l|}{ Education status } \\
\hline Illiterate & 90 & 25.00 \\
\hline Primary & 72 & 20.00 \\
\hline Middle & 82 & 22.77 \\
\hline Higher secondary & 65 & 18.05 \\
\hline Graduate and above & 41 & 11.38 \\
\hline \multicolumn{3}{|l|}{ Occupation } \\
\hline Employed & 115 & 31.94 \\
\hline Unemployed/ Housewife & 245 & 68.05 \\
\hline \multicolumn{3}{|l|}{ Religion } \\
\hline Hindu & 261 & 72.50 \\
\hline Muslim & 43 & 11.94 \\
\hline Others & 56 & 15.55 \\
\hline
\end{tabular}

Table 2: Knowledge regarding Childhood Immunization

\begin{tabular}{|l|c|c|}
\hline $\begin{array}{l}\text { Knowledge regarding Childhood } \\
\text { Immunization }\end{array}$ & No. & $\%$ \\
\hline $\begin{array}{l}\text { Knowledge regarding age related } \\
\text { vaccination }\end{array}$ & 113 & 31.38 \\
\hline Vaccine preventable diseases & 25 & 0.55 \\
\hline Age at which vaccination should started & 192 & 53.33 \\
\hline Age at which vaccination get completed & 180 & 50.00 \\
\hline Vaccines are safe & 205 & 56.94 \\
\hline Action to be taken in case of side effect & 135 & 37.5 \\
\hline $\begin{array}{l}\text { Awareness regarding all four key } \\
\text { messages }\end{array}$ & 53 & 14.72 \\
\hline Benefits of childhood immunization & 173 & 48.05 \\
\hline $\begin{array}{l}\text { Condition in which vaccination is to be } \\
\text { postponed }\end{array}$ & 47 & 13.05 \\
\hline
\end{tabular}

Table 3: source of information regarding immunization

\begin{tabular}{|l|c|}
\hline Source of Knowledge & $\%$ \\
\hline Television/ Radio & 3.33 \\
\hline Health Worker & 56.94 \\
\hline Anganwadi Worker & 9.72 \\
\hline Hospital/Doctors & 7.77 \\
\hline Neighbours/ Relatives & 12.5 \\
\hline
\end{tabular}

Table 04: Age specific Immunization status of Child

\begin{tabular}{|l|c|c|}
\hline $\begin{array}{l}\text { Age specific Immunization } \\
\text { status of Child }\end{array}$ & $\begin{array}{c}\text { No. of } \\
\text { children }\end{array}$ & $\begin{array}{c}\% \text { of } \\
\text { children }\end{array}$ \\
\hline Incomplete & 107 & 29.72 \\
\hline Complete & 253 & 70.27 \\
\hline Total & 360 & 100 \\
\hline
\end{tabular}


Table 5: Reasons for incomplete age specific immunization

\begin{tabular}{|l|c|c|}
\hline $\begin{array}{l}\text { Reasons for incomplete age specific } \\
\text { immunization }\end{array}$ & No. & $\%$ \\
\hline Lack of time & 16 & 14.95 \\
\hline Family problem & 13 & 12.14 \\
\hline Child Illness & 12 & 11.21 \\
\hline Inconvenient time of session & 09 & 8.41 \\
\hline $\begin{array}{l}\text { Lack of awareness of next/further } \\
\text { dose }\end{array}$ & 27 & 25.23 \\
\hline $\begin{array}{l}\text { Lack of awareness for need of } \\
\text { Vaccination }\end{array}$ & 00 & 00 \\
\hline $\begin{array}{l}\text { Mother was unaware of age related } \\
\text { vaccination }\end{array}$ & 05 & 04.67 \\
\hline $\begin{array}{l}\text { Deficient information of place and } \\
\text { time for session }\end{array}$ & 11 & 10.28 \\
\hline Unavailable vaccines & 06 & 05.60 \\
\hline No belief in the vaccination & 00 & 00 \\
\hline Fear of side effect & 08 & 07.47 \\
\hline
\end{tabular}

Figure 01: Source of Information

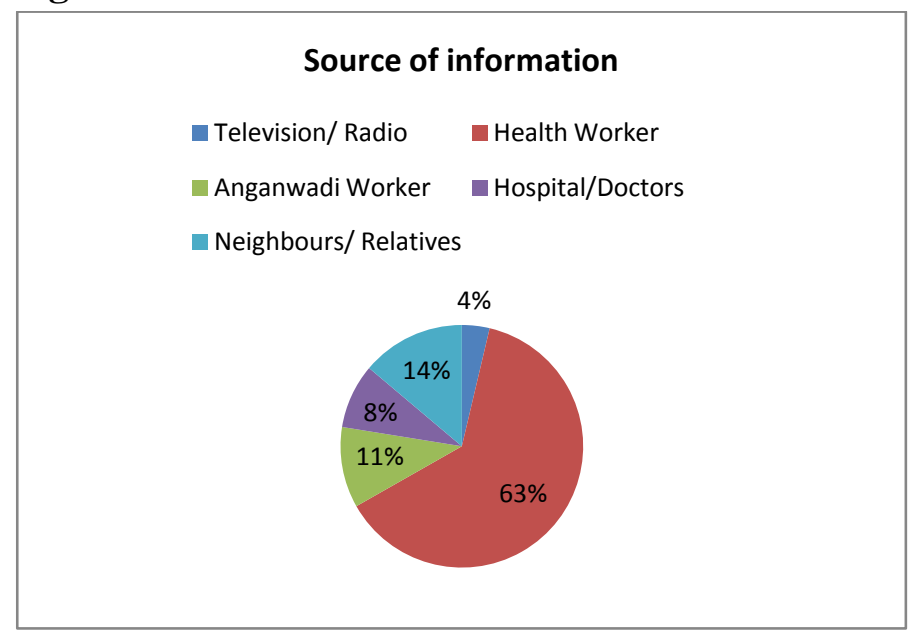

\section{Discussions}

Immunization is a proven tool for controlling and eliminating life-threatening infectious diseases. It is one of the most cost effective health investments, which make it accessible to even the most hard-to-reach and vulnerable populations. Despite this, vaccine preventable diseases remain the most common cause of childhood mortality. Uptake of vaccination services is dependent not only on provision of these services but also on other factors including knowledge and attitude of caregivers. As for as Demographic Profile of Caregivers is concerned in present study out of 360 caregivers interviewed majority of $(43.61 \%)$ belonged to 21-30 yrs age group and $10.83 \%$ were less than 20 years. which may be due to the regional tradition of early marriages. With regard to education status $25.00 \%$ were illiterate, $72(20.00 \%)$ completed primary schooling, $82(22.77 \%)$ received educations up to middle only $11.38 \%$ caregivers were graduate and above. By employment 115(31.94\%) caregivers were employed and remaining $68.05 \%$ were either unemployed or housewife. Religion wise majority of caregivers $261(72.50 \%)$ belonged to Hindu religion, $11.94 \%$ were Muslims and rest of $15.55 \%$ were from other religions. These findings were similar to the study carried out by Sarfaraz Md et al that majority of mothers were in the age group of 21-25 yrs [79 (76.69\%)] while 5 (4.85\%) mothers in the age group below $20 \mathrm{yrs}$. mothers most of mothers were $74.75 \%$ were uneducated, $10.6 \%$ completed primary schooling, $9.7 \%$ completed secondary schooling and $1.9 \%$ completed degree, indicated $97 \%$ mothers were homemakers, $75(72.81 \%)$ parents were Hindu, 25 (24.27\%) were Muslims and $3(2.91 \%)$ were Christians. ${ }^{[10]}$ With regard to education and occupation similar finding was shown in study carried out by Hamid $\mathrm{S}$ et al, Rabbanie Tariq Wani et al and Ramalingam R . Hamid $S$ et al found that $80 \%$ mothers were illiterate or had only primary education and $93 \%$ were house wives. ${ }^{[7]}$ Rabbanie TW et al noticed that Majority of the mothers were educated up to preschool $(61.60 \%)$ and most of them were Housewives $(63.30 \%) .{ }^{[12]}$

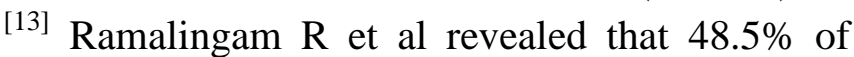
mothers were educated until primary school. ${ }^{[14]}$ but education related finding is in contrast to the study conducted by by Holyachi $\mathrm{S}$ that $\%$ of study participants were literate. ${ }^{[15]}$

With regard to Knowledge regarding childhood immunization around 192(53.33\%) of the caregivers knew when vaccination was to be initiated and $50 \%$ were aware when vaccination get completed, a majority of the mothers $56.94 \%$ believed that vaccines are safe and $48.05 \%$ caregiver consider vaccine are beneficial, $31.38 \%$ mothers were aware of age related vaccination, only $0.55 \%$ caregivers knew vaccine preventable disease. Finding in present study related to 
knowledge regarding childhood immunization, age at which vaccination is to be initiated, age at which vaccination get completed, safety and benefits of vaccination were similar to finding of study carried out by Hamid S et al, Rabbanie TW et al and similar finding related to benefits of vaccination was observed by Priyesh $\mathrm{M}$ et al. Hamid S et al found that all the mothers (100\%) had the knowledge that immunization is important and beneficial for the child, knew that immunization is to be started at birth, shown view that there is no problem with vaccination, considered that vaccination should be completed as per schedule and side-effects not dangerous. ${ }^{[7]}$ Rabbanie TW et al revealed in their study that most of the mothers knew the correct age to start vaccination. Most of them believe that vaccines are not harmful. Majority of the mothers believes that vaccination is important and to follow the vaccination schedule for good health. ${ }^{[12]}$ Priyesh $M$ et al in their study noticed that out of 150 mothers, 123 (82\%) mothers knew about the benefits of immunization. ${ }^{[13]}$

The main source of information regarding childhood vaccination was health workers 205 mainly through the Asha worker, other source of information were Aaganwadi worker, Neighbours/ Relatives, hospital and TV/ Radio. finding our study related to source of information is similar finding of hamid $\mathrm{S}$ et al. Sarfaraz $\mathrm{Md}$ et al, Vasantha $\mathrm{KC}$ et al and Ramalingam $\mathrm{R}$ et al, hamid $\mathrm{S}$ et al revealed health workers were the main source of information $(88 \%) \cdot{ }^{[7]}$ In a similar study Sarfaraz Md et al in their study observed that the main source of information regarding vaccination was Anganwadi 81 (78.6\%) mainly the Asha health care workers. ${ }^{[10]}$ Ramalingam R et al found that majorly of mothers acquired through health-care workers $(76.5 \%)$. Vasantha $\mathrm{KC}$ et al shown that $96 \%$ of the mothers reported health care personnel as a source of information. ${ }^{[16]}$

Age specific immunization status in present study revealed that $107(29.72 \%)$ children partially immunized, remaining $253(70.27 \%$ ) children were completely immunized. Similar finding was found in different study conducted by Hamid $S$ et al, Sarfaraz Md et al, Priyesh M et al, Mugada V et al and Siddiqui NS et al that most of children were completely immunized. [7], [10], [13], [17], [18] but This observation in our study is contrast to the study conducted by Vasantha $\mathrm{KC}$ et al where they found that $80 \%$ of the under five children are partially immunized whereas only $10(20 \%)$ of them are fully immunized. ${ }^{[16]}$

In our study it was seen that among 107 partially immunized children-lack of awareness of next/further dose $(25.23 \%)$ was found to be the major reason for incomplete immunization. Other reasons for incomplete immunization were lack of time $(14.95 \%)$, certain family problems $(12.14 \%)$, child illness $(11.21 \%)$, inconvenient time of session for working women $(8.41 \%)$, Mother was unaware of age related vaccination (04.67\%), Deficient information of place and time for session $(10.28 \%)$, Fear of side effect $(07.47 \%)$, Unavailability of vaccines (05.60\%). Hamid S et al also observed unawareness and sickness of child as reason for partial immunization. Varied reasons were given for not completing the immunization on schedule including uncooperative husband or busy in house-hold work. ${ }^{[7]}$ Rabbanie TW et al in a similar study found child illness(from cold and fever) as main reason of incomplete immunization. ${ }^{[12]}$ A study conducted by Ramalingam $\mathrm{R}$ revealed that $44 \%$ of mothers were unwilling to get the their child immunized due to the fear of side effects of vaccine. ${ }^{[14]}$ Mugada $\mathrm{V}$ et al in their study revealed that unavailability of vaccine was considered to be the major reason for incomplete immunization. Other reasons for incomplete immunization were unawareness of mother regarding age related vaccines, the child was ill-was brought and was not immunized, unawareness of need for immunization. ${ }^{[17]}$

\section{Conclusion}

Lack of awareness of next/further dose of vaccine was found to be the major reason for incomplete 
immunization. So there is a need to increase awareness and knowledge about the benefits of vaccination, as well as the potential disadvantage of partial immunization. IEC activities must be increased in immunization clinics to improve the awareness of community; audio visual aid should be used to narrating the importance of vaccination focusing on illiterate and backward section of society. Health workers and medical personnel should educate the parents about the importance of routine immunization.

\section{Source of support: nil}

\section{References}

1. Handbook for vaccine and cold chain handlers, Department of Health and Family Welfare, Ministry of Health and Family Welfare Government of India $2^{\text {nd }}$ edition 2016

2. Immunization handbook for health worker. Department of Health and Family Welfare, Ministry of Health and Family Welfare Government of India. Revised edition 2011

3. Park K. Park's Textbook of Preventive and Social Medicine. M/S Banarsidas Bhanot Publishers, 23 ${ }^{\text {rd }}$ Edition 2015 P122

4. J.Kishore's National Health Programs of India. Century Publications, $11^{\text {th }}$ edition 2014 P178

5. Kapoor R, Vyas S; Awareness and knowledge of mothers of under five children regarding immunization in Ahmadabad. Healthline,Journal of Indian Association of Preventive and Social Medicine, 2010;1(1):12-5.

6. Government of India. Immunization Handbook for Medical Officers. Department of Health and Family Welfare. Ministry of Health \& Family Welfare. Edition;2008:15

7. Hamid S, Andrabi SAH, Fazli A, Jabeen R. Immunization of children in a rural area of North Kashmir A KAP STUDY. Online
Journal of Health and Allied Sciences. 2012; 11(1):10.

8. Juny Sebastian, Gurumurthy Parthasarathi. Mandyam Dhati Ravi. Development of Knowledge, Attitude and Practice Questionnaire of Parents towards Vaccination: Process, Challenges and Solutions. Indian Journal of Pharmacy Practice.2017: 10(2); 115-20

9. Awadh AI, Hassali MA, Al-lela OQ, Bux SH, Elkalmi RM, Hadi H. Immunization knowledge and practice among Malaysian parents: a questionnaire development and pilot-testing. BMC public health. 2014:14 (1); 1107.

10. Sarfaraz Md, Athira A, Thotamsetty LMD, Ravilla SA, Nadikudi N, Doddayya $\mathrm{H}$. Assessment of knowledge, attitude and perception among mothers towards immunization in a tertiary care teaching hospital. Int $\mathrm{J}$ Community Med Public Health 2017;4:3429-35.

11. Nisar N, Mirza M, Qadri MH. Knowledge, Attitude and Practices of mothers regarding immunization of one year old child at Mawatch Goth, Kemari Town, Karachi. Pak J Med Sci 2010;26(1):183-186

12. Rabbanie Tariq Wani, Hibba Dar, Zahoor Ahmad Raina. Knowledge, Attitude and Practices of Mothers with Children Under Five Years of Age About Vaccination. Journal of Medical science and clinical research.2017;5(7):24449-54

13. Marskole P, Rawat R, Chouhan P, Sahu P, Choudhary R. Knowledge, Attitude and Practices on Vaccination among Mothers of under-5 Children, Attending Immunization Out Patients Department at Gwalior, Madhya Pradesh. Int J Sci Stud 2016;3(12):235-237.

14. Ramalingam R, Ajay, Chetty S. Assessment of knowledge, attitude and practice of antenatal mothers on child's immunization in Raichur district, Karnataka. Indian $\mathbf{J}$ Child Health. 2017; 4(1):57-60. 
15. Holyachi S, Kengnal RP, Kumar A. Parental perception of childhood vaccination through focused group discussion approach amongst women in Karnataka, India. Natl J Community Med 2018; 9(1): 19-24

16. Vasantha KC and Xavier BC.2016, Knowledge, Attitude And Practice of Mothers of Under Five Children Regarding Immunization In A Selected Community, Rishikesh, Uttarakhand. Int J Recent Sci Res. 7(5), pp. 11301-11305.

17. Mugada V, Chandrabhotla S, Kaja DS, Machara SGK. Knowledge towards childhood immunization among mothers \& reasons for incomplete immunization. J App Pharm Sci, 2017; 7 (10): 157-161.

18. Siddiqui NS, Gaikwad AK, Kuril BM, Ankushe RT, Doibale MK, Pund SB, Kumar P. Is mothers' knowledge and practice regarding childhood immunization compliant with immunization completeness? Int J Community Med Public Health 2017;4:775-80. 